\title{
A Systematic Review Exploring the Impact of Social Media on Breastfeeding Practices \\ Lisa Orchard, Wendy Nicholls
}

\begin{abstract}
Social media has potential to promote and support positive health behaviours. This systematic review explores the influence of social media on breastfeeding decision-making, promotion and support. For the purpose of the review, social media was defined as social networking sites and blogs; M-technology and apps were only considered if they included an interactive element, such as a 'share' function, or one-to-many communication. Searches were conducted on EBSCO across seven databases (limited to 2007-2019). Of the 1261 papers initially identified, 22 met the inclusion criteria for the current review. Results are mixed, but there is evidence that social media can be used to improve breastfeeding awareness and attitudes. Breastfeeding mothers value pro-breastfeeding online communities. However, the success of such social media groups may be dependent on specific content shared, individual contributors, and group dynamics. Key considerations for practitioners are offered regarding how social media can augment services offered to support breastfeeding. Research in this field is still very much in its infancy. Further investigation of specific social media content is needed, alongside the viewpoints of those who have ceased breastfeeding against their wishes.
\end{abstract}

Keywords: nursing, infant feeding, chestfeeding, Twitter, Facebook 


\section{Introduction}

Breastfeeding is a global health priority and an essential part of the 2030 agenda for Sustainable Development set out by the World Health Organization (WHO) (UNICEF, 2016). Despite this global importance, rates vary considerably across the world, and many countries struggle to reach recommended benchmarks. As an example, WHO data from 2007-2014 (WHO, 2018) suggest that worldwide only $36 \%$ of infants aged 0-6 months are exclusively breastfed. Although regional data is difficult to obtain due to data availability, research up to 2012 suggests that $43 \%$ of infants in the WHO South-East Asia Region were exclusively breastfeeding at 6 months, compared to only $25 \%$ of infants in the WHO European Region (WHO, 2015). Given that not breastfeeding has been shown to be associated with adverse health risks leading to subsequent economic costs (Renfrew et al., 2012; Stuebe, 2009), it is important to explore potential avenues to improve breastfeeding support and promotion.

It may first be useful to explore the reasons why women stop breastfeeding, in order to look at ways this trend could be countered. Reasons include medical issues (e.g. tongue tie, or special care babies); early introduction of artificial milk; and social issues, such as level of support and acceptability of breastfeeding among friends, family and the public (Royal College of Paediatrics and Child Health, 2019). Public Health England (PHE) reported that " $81 \%$ of mothers who breastfed for less than a week and $86 \%$ of mothers who breastfed for between one and two weeks said they would have liked to have breastfed for longer" (McAndrew et al., 2012, p. 112). Further, $17 \%$ of mothers thought that having "more support and guidance from hospital staff, midwives and family" would have influenced them to breastfeed for longer (McAndrew et al., 2012). A review by Rollins et al. (2016) supports this finding at an International level, 
concluding that it is possible to improve breastfeeding rates with appropriate interventions, which support women in the home and community.

Social media has become the first point of call when interacting with the online world and may be a medium through which support for breastfeeding women can be channeled. Indeed, social media's potential as a health promotion tool has already been recognised (Korda \& Itani, 2013). Further, Jin, Phua and Lee (2015) argue that social media may be key in promoting health messages, given its wide-reach, low cost and previous success. There are many reasons people may be drawn towards using social media, including a need to belong, to make new connections, and to seek information (Orchard, 2019). The ability to fulfil these motivations, partnered with the ease and accessibility of 'app' technology, suggests that social media holds potential as a facilitator to health support and promotion. With regards to breastfeeding, social media may be particularly effective in reaching the target audience given that new mothers often report increased levels of loneliness (Lee, Vasileiou \& Barnett, 2017), and technology may be their only source of socialisation and entertainment during nocturnal cluster feeds. However, it has been argued that face-to-face breastfeeding support is an important facet of best practice (Cleminson, Oddie \& Renfrew, 2015), which poses questions over how social media can be best used.

Dedicated breastfeeding pages (on Facebook, for example) allow direct access to information, while the sharing of memes and infographics means that information may be accessed implicitly without directly searching for it. The 'Theory of Planned Behaviour' (Ajzen, 1985) emphasises the strong influence of subjective norms on behavioural intentions and continued behaviour. Trending hashtags, such as \#normlisebreastfeeding and \#informedisbest, may have the power to build a stronger breastfeeding community, through informing social 
norms. Indeed, Xu, Chiu, Chen, and Mukherjee (2015) argue that hashtags allow for effective community development. However, social media may also have pitfalls. For instance, the sharing of misinformation or breastfeeding 'horror stories' have the potential to contribute to a norm of artificial milk and, although often shared with the best intentions, these could be detrimental to breastfeeding promotion and support (Cross-Barnet, Augustyn, Gross, Resnik \& Paige, 2012).

To use social media in its most effective manner, it's important to first establish what research has found so far in this regard. The aim of this systematic review is therefore to highlight research evidence where social media offers potential as a medium of breastfeeding promotion, decision-making, and support; and in doing so, to inform practitioners and service providers as to how best utilise social media for promoting positive breastfeeding behaviour.

\section{Method}

To ensure methodological rigour, objectivity, and replicability, standard methodology for systematic reviewing (Moher, Liberati, Tetzlaff, Altman, 2009) was applied. The review protocol was registered on PROSPERO (CRD42018109095) and aims, inclusion criteria, data extraction, and data quality evaluation were specified at the outset. The review refers to Khan et al.'s (2003) five-step approach to systematic reviews as a structural guide.

\section{Framing questions and Literature Identification}

The current review aims to address the following question: "What role can social media play in the promotion or maintenance of breastfeeding?" To identify literature, two searches were conducted. The initial search was conducted on $25^{\text {th }}$ October 2018. A secondary search on 
$14^{\text {th }}$ August 2019 was conducted to update results and ensure that new papers published during the write up period were captured to ensure currency. Searches were conducted across seven EBSCO databases (Academic Search Complete, Behavioral Science Collection, PsychINFO, Child Development \& Adolescent Studies, CINAHL Plus, Medline, SocINDEX), which were selected as they primarily index journals related to psychology and/or health and limited to results from 2007-2019. This time period was selected as 2007 coincides with the onset of Facebook's popularity. Facebook's dominance could arguably be considered the catalyst for social media's traction. Search terms followed two strands: words relating to breastfeeding, and words relating to social media (see Supporting Information for the full search strategy).

Inclusion and exclusion criteria were specified a priori in the review protocol. Included articles needed to satisfy the following inclusion criteria:

a. Articles must be peer reviewed

b. Articles must be in English Language

c. Articles must be published between 2007-present.

d. Articles must be empirical (including the collection of and analysis of original data).

e. Articles must be in the English language

f. Qualitative articles must discuss both social media and breastfeeding.

g. Quantitative studies must measure variables relating to breastfeeding and/or breastfeeding behaviour, alongside variables associated with social media usage. 
g. The participants should include individuals from one or more of the following groups:

breastfeeding mothers, pregnant mothers, parents, and expecting or prospective parents.

Prospective parents were not included in the protocol but were incorporated post hoc based on the relevance of findings from papers that included this group.

Articles were excluded if they were review articles, protocols, conference abstracts, unpublished theses, or editorials/book reviews.

Figure 1 provides an overview of inclusions at each stage of the review. The first search yielded 1,123 results. Following EndNote importation and de-duplication, the titles of 896 papers were independently screened by two reviewers using the protocol as guidance. An additional 138 papers were identified through the second, updated search and independently screened by the same two reviewers. Where disagreements were identified, article abstracts were consulted to help reach an agreement. Following the title screen of both searches, the abstracts (and full text where required) from 105 records were screened against the inclusion criteria. This resulted in a further 83 studies being excluded. For clarity, the predominant reason of exclusion is reported here. However, some papers fitted more than one category:

a. Thirty-six papers studied a technology that was not classed as social media under the authors' pre-defined definition. ${ }^{1}$

\footnotetext{
${ }^{1}$ Social media does not have a definitive definition, making the inclusion of technologies subjective. Although social networking sites, such as Facebook, Twitter and Instagram, are easily recognised as a form of social media, there is ambiguity surrounding other forms of technology, such as WhatsApp. Within the current review, text messages, videos, general Internet usage, and phone calls were not classed as social media. 'Apps' were only considered a form of social media if the app itself allowed for interactivity between multiple users (specifically, facilitating communication with other non-health professionals). Blogs were considered a form of social media as they were presumed to fulfil the requirement of interactivity through commenting,
} 
b. Twenty-three references were non-empirical, or from an excluded format (such as an existing literature or general narrative paper).

c. Fourteen papers did not measure variables specific to breastfeeding.

d. Nine papers included social media as a method of data collection, as opposed to a variable of interest.

e. One paper was not in English.

Twenty-two papers were included in the final review. Given the breadth of the review scope, a grey literature search was not included. The use of social media as a key search term appeared problematic for finding relevant papers outside of the search databases. This may be considered a limitation of the search given that further research in the area may be available.

[INSERT FIGURE 1 HERE]

Figure 1: Selection of studies for inclusion

Data extraction was managed through Microsoft Excel. Information was captured in relation to the sample, research questions and aims, variable information in relation to social media and breastfeeding, limitations, and implications for practice.

\section{Quality Assessment}

Within the present review, study designs were expected to vary in line with their research questions and aims. Therefore, our requirements were that the quality tool should be appropriate

\footnotetext{
'liking', and shares. Discussion boards outside of specified social media platforms were not classed as social media given their traditional reliance on anonymity and that they are not historically classed as a web 2.0 development.
} 
for randomised controlled trials, quantitative and qualitative studies. Kmet, Lee \& Cook (2003) formulated the QualSyst as a pragmatic quality review tool, which would apply to RCTs, qualitative, and quantitative designs. This quality review tool has since been applied extensively, particularly within health sciences, and in reviews where both qualitative and quantitative data are considered (e.g., Chen, Xiang, Janet, Chen, He, \& Vivian, 2020), and was therefore assessed as suitable for the present review.

Using the published manuals for quality scoring (Kmet, et al., 2003), both authors independently rated the quality of included papers. Quantitative papers were rated across 14 criteria and qualitative papers across 10 criteria. Each item was scored as follows; $0=$ criteria not fulfilled, 1 = criteria partially fulfilled, 2 = criteria fulfilled well, $\mathrm{X}=$ not relevant. Two mixed methods papers were assessed against the quantitative criteria as this data was the main focus of their research. Inter rater reliability analysis identified $84 \%$ agreement across a sample of four records. Summary scores were calculated for each paper, as per the method described in the manual. For quantitative studies, the total score obtained across relevant criteria was summed and then divided by the total possible score (i.e.: 28 - (number of $X^{* 2}$ )). For qualitative studies, the same principle was applied, noting that scoring $X$ was not permitted for any of the items.

The present review did not employ a threshold for inclusion based on data quality scores. Given the paucity of literature on this topic, it was decided to include all available data, and to interpret with caution those studies that were relatively weaker; identified as those scoring below a relatively liberal threshold of .55. Quality scores were used to compare quality between included studies and also across particular elements of method and design. Data quality assessment assisted with an explanation of any heterogeneity in findings and with understanding 
general weaknesses in the extant literature, which inform recommendations from this review for future research.

\section{Results}

Twenty-two studies were included in this review: fifteen using qualitative methods, five using quantitative methods, and two using mixed method (classified as quantitative for data quality purposes). Studies were based across nine countries (see Table 1).

\section{Table 1: Extraction Table}

[INSERT TABLE 1 HERE]

\section{Data Quality}

The summary score is a ratio of 'achieved score:possible score' and therefore is presented as a decimal value up to 1 , with a higher score indicating better quality (Kmet et al., 2004). Across all studies the mean summary score for data quality was $0.77(\mathrm{SD}=0.17, \mathrm{n}=22)$. The range was 0.39 (Tomfohrde et al., 2016) to 1 (Jin et al, 2015). Four studies scored below .55 (Alianmoghaddam, Phibbs, \& Benn, 2019; Kallem, Gruver, Virudachalam, and Fiks, 2018; Majee et al, 2017; Tomfohrde \& Reinke, 2016). Whilst the findings from these studies are included in the synthesis, they should be interpreted with caution.

Mean scores for individual criteria were inspected to look for overall trends in the quality of the included studies. Overall qualitative studies performed well with regards to design. Studies clearly defined the context, and connected to a wider theory in regards to the methodological framework. Studies also had a clear description of findings. Studies performed poorly on 
providing evidence of reflexivity. Conclusions also went beyond the scope of the findings. Quantitative studies performed well on sample size and clearly describing findings. Studies performed relatively poorly on controlling for confounding variables. For instance, the RCTs (Niela-Vilén et al., 2016; Cavalcanti, Cabral, de Toledo Vianna and Osório, 2019) did not make it clear whether they controlled for use of other social media. Studies also performed poorly on reporting of estimates of variance. Data reporting in analyses was not consistent enough to allow for meta-analysis. For the most part, effect sizes and estimates of variance were not reported or were not appropriate to report. Furthermore, predictor and outcome measures needed further clarification. For example, Cavalcanti et al. (2019) alluded to the psychological mechanism through which the intervention had worked, when these data do not appear to have been gathered through identified outcomes. Finally, participant descriptions were incomplete. For instance, age reporting of mothers and infants were inconsistent; some studies reported age categorically, whilst others did not, or could not, report this information. Parental or child health issues were rarely identified. Furthermore, the population type (antenatal vs. postnatal) was often implicit but not clarified.

\section{Synthesis of papers}

Studies were organised into five themes formed through research question similarities. These were: Facets of infant feeding; Social media usage amongst breastfeeding mothers; Impact of existing social media; Interventions and Content Impact; and Online community experiences.

\section{Facets of infant feeding.}

Six studies indirectly discuss social media as a facet of breastfeeding; that is, social media and breastfeeding were discussed, but they were not the main focus of the study. Thepha, 
Marias, Bell and Muangpin, (2018) interviewed thirty mothers with children aged 4-6 months to explore facilitators and barriers to exclusive breastfeeding until six months. Social media was discussed by participants as a facilitator of breastfeeding by allowing fulfillment of informationseeking needs and support needs. Similarly, Majee, et al. (2017) interviewed co-parents to discuss infant feeding decisions, finding that parents identified social media as a means of health information-seeking and sharing. However, it should be noted that mothers identified social media as being complementary to other sources of help. Guerra-Reyes, Christie, Prabhakar, Harris, \& Siek, (2016) provides insight to such need for information. The researchers interviewed low-income postpartum mothers about general information seeking through mobile phones. Participants reported a number of reasons for using social media and app technology, including to seek out support for establishing breastfeeding and information on related issues (e.g. tongue-tie), general health and behavioural issues, and topics that they found too uncomfortable to discuss face-to-face.

Although these results appear positive, there may be caveats for the level of importance social media holds. Hauck et al. (2016) also identified social media as a facilitator of breastfeeding support. The cross-cultural exploratory study used critical incident technique to study women's perceptions of support mechanisms to continue breastfeeding for six months. While informal online support was ranked as the second most important support mechanism by Irish participants, it only ranked as ninth and tenth respectively for Swedish and Australian participants. Cueva et al. (2017) evaluated a breastfeeding counsellor programme and found social media to be integral to its wider nutrition programme. One co-ordinator is quoted as saying: "The Facebook page is incredible... I don't want to say it's our biggest success, but it is pretty amazing how successful it is." (p. 862). Staff throughout the study identified the usefulness 
of online support groups, but emphasised that this should be supplementary to in-person groupings, rather than as a replacement. Finally, in an analysis of Facebook posts as part of a wider intervention towards improved infant health, Kallem et al. (2018) found evidence of social media being used for information and support. Seven out of 61 questions posted in the Facebook group specifically asked about breastfeeding. One out of 12 responses to breastfeeding questions within the group contradicted official health guidelines.

\section{Social media usage amongst breastfeeding mothers.}

Two studies researched general social media uptake by this population. A group of mothers who were currently breastfeeding or who had nursed within the previous five years were asked about their social media usage (Tomfohrde \& Reinke, 2016). Results indicated a strong prevalence of social media use in the target population, with $96 \%$ of respondents using social media whilst breastfeeding, and 92\% indicating that they used Facebook specifically. Those not using social media were unaccounted for, which would inevitably inflate these figures. Within this group, $49 \%$ of respondents reported using social media often whilst breastfeeding, with $27 \%$ claiming they used it "all the time". However, these figures appear to relate to generic social media use, as opposed to seeking out breastfeeding specific support or information. Indeed, $76 \%$ of respondents suggested they were motivated by entertainment, compared to only $31 \%$ who used it to connect to other breastfeeding mothers. Results may have been different if focusing on new mothers within the early days of their breastfeeding journey.

Ethnographic research studying social media usage of first-time African-American mothers and their support persons (Asiodu et al., 2015) also reports widespread social media use, suggesting that participants accessed diverse platforms across smartphones and/or computers. 
The research found that participants and support persons frequently used social media within the antenatal period for health education and social support from others. Usage within postpartum periods became more targeted, specifically for support. However, it should be noted that despite $93 \%$ of mothers intending to breastfeed initially, only $29 \%$ were doing so exclusively at three months. The authors argue that those who continued to breastfeed found social media invaluable, but it was not being used to its full potential.

\section{Impact of existing social media.}

Two studies broadly explored the impact of social media on breastfeeding. Gallegos et al. (2011) ran six focus groups to explore the potential of technology, including social media, to reduce risks associated with breastfeeding. The study recruited 41 women via Australian childcare centres. This included women who had breastfed and those who had formula fed (by choice or otherwise), but no further description was provided. A grounded theory approach identified that technology helped to ease the uncertainty around breastfeeding. Furthermore, social media was seen as a safe space to validate their breastfeeding decisions. Alianmoghaddam et al. (2019) conducted a longitudinal qualitative study to explore the impact of social media on exclusive breastfeeding practice. Thirty participants were interviewed four to six weeks after birth, and then followed up with short, five-minute telephone interviews up until six months or breastfeeding cessation. The paper specifies four key themes within the results. Specifically, mothers use social media for information seeking; apps are seen as a good option for breastfeeding promotion; weak ties facilitate information sharing; and Skype can be used as an offline support facilitator. The results suggest that social media should play a key role in breastfeeding promotion and information; though support may not hold the same weight as 
offline support due to a lack of physical proximity. Participants were intending to breastfeed from the beginning, which may have biased results.

In addition, two studies looked at types of breastfeeding content. West et al. (2011) explored the usefulness of blogs on breastfeeding practice by providing a breakdown of the type of information found in breastfeeding-specific blog postings using the integrated behavioral model. Content analysis was used to analyse posts. Most commonly, $28.5 \%$ of posts discussed attitudes towards breastfeeding (either positive or negative). This was followed by consciousness raising $(25.3 \%)$, behavioural cues $(23.8 \%)$, barriers $(13.3 \%)$, benefits $(13.3 \%)$, and intentions to breastfeed $(10.2 \%)$. The paper concludes that blogs allow for communication of behaviour support. Furthermore, blogs affiliated with industry may be more effective than personal blogs. The diversity of content suggests that blogs may have the potential to facilitate changes to social norms around breastfeeding. Marcon, Bieber and Azad (2019) analysed breastfeeding content within Instagram. The study gathered 4089 images and 8331 comments from four breastfeedingrelated hashtags over the duration of a week. In terms of popularity, \#breastfeeding produced the most content; which was followed by \#breastmilk, \#normalizebreastfeeding and \#breastisbest. There were also differences in the type of content under each hashtag, though content was found to be predominantly positive. Less than $0.5 \%$ of images represented antagonistic content; whilst commenting contained high instances of praise (92\%) and thanks (47\%). Furthermore, content was predominantly personal (as opposed to educational). The authors argue that such content would allow for the development of supportive networks through shared experiences and confidence building. 


\section{Interventions and Content Impact.}

Four studies explicitly discussed social media interventions. Biediger-Friedman, Silva, and Smith, (2018) set up six focus groups to evaluate a pre-designed health app (incorporating breastfeeding). Although apps were generally excluded from the review, this particular app incorporated a 'share' function, linking activity with Facebook and Pinterest. This share feature was described by the authors as a "promoter for motivating behaviors" (p.118). Bahkali et al. (2015) explored the impact of a women's health campaign Twitter account on breastfeeding awareness, attitudes and behavioural promotion in Saudi Arabia. The intervention itself lacks detail, but the authors write that such information "included questions from and answers to mothers, the sharing of videos, sending of educational messages, graphs, and synchronous and asynchronous communication" (p. 248). Pre- and post- measurements were not recorded, and followers may have been following the account for differing amounts of time. It is also not clear that followers were breastfeeding, or even whether they were mothers. However, self-reported responses were promising, with a reported increase in the level of user awareness for breastfeeding based on self-assessed knowledge before following the Twitter feed $(95.5 \%, n=$ 462), with 57.4\% ( $\mathrm{n}=278$ ) reporting a high score for increased awareness. Furthermore, approximately half of participants reported that the Twitter account had a positive impact on starting or continuing breastfeeding $(52.7 \%, n=255)$.

Mixed success has been found for delivery of interventions via Facebook. An RCT exploring the impact of a Facebook group on breastfeeding outcomes (specifically duration of breastfeeding/ breast milk expression and maternal breastfeeding attitude) found limited impact on breastfeeding behaviours (Niela-Vilén et al., 2016). The RCT recruited mothers of preterm infants. The experimental group $(n=60)$ of participants were invited to participate in a closed 
breastfeeding peer-support group, however, they were under no obligation to visit the group. Control group participants $(n=64)$ were not offered the chance to join this group. The group itself was managed by a midwife and three voluntary mothers with experience of breastfeeding a preterm infant. Those visiting the peer support group reported that they found it accessible and enjoyable. However, only $26 \%$ reported a perceived impact on their breastfeeding behaviours. The average duration (median) of overall breastfeeding was 3 months for the experimental group and 4.3 months for the control group (non-significant difference). Further, the intervention was found to have no effect on duration of breastfeeding or attitude to breastfeeding. A more recent RCT (Cavalcanti et al, 2019) conducted in Brazil had more success. The RCT recruited 123 mother-child pairings to a Facebook group intervention and compared the results with a control group $(\mathrm{n}=128)$. Group engagement was encouraged with weekly posts, which individuals were tagged into. Mothers were interviewed on a monthly basis. Results found that the intervention group held a significantly higher number of mothers exclusively breastfeeding at each stage. After six months, the intervention group had a $33.3 \%$ success rate, compared to $8.3 \%$ in the control group.

These studies provide a useful insight into the direct impact of social media. However, while the social media content is impacting upon these outcomes, the content itself is not being directly studied in these studies. Two papers explored specific social media content. Jin, Phua and Lee (2015) made subtle content manipulations within a mock Facebook breastfeeding page to explore impact upon a variety of breastfeeding outcomes for those without breastfeeding experience. Specifically, the experiment explored the impact of message style within Facebook comments (i.e. mothers' testimonials, expert information, or mixed) and page popularity (high or low, as measured through page likes, shares, and comment likes). Expert messages were more 
credible and informative than mothers' testimonies or mixed comments. Popular pages resulted in higher perceived credibility of commenters, a higher perception of information value, a stronger intention to provide online social support for commenters, and higher wishful identification with the commenters on the page. It appears that having mixed comments from experts and mothers' testimonies within a popular page is most effective at impacting positively upon breastfeeding outcomes and attitudes. In a second experiment, the authors explored the effect of comment valence (i.e. the effect of seeing comments relaying a successful breastfeeding journey, vs a failed breastfeeding journey, vs mixed), alongside page popularity (high vs low). Success stories resulted in higher source credibility, wishful identification with commenters, social identification with commenters, interpersonal attraction with commenters, willingness to build online friendship with commenters, and role model perception. On the other hand, failure stories resulted in significantly higher empathy. Popularity of pages was again significant, with more popular pages resulting in a higher breastfeeding intention, higher altruism, a more positive attitude towards breastfeeding, and stronger breastfeeding self-efficacy. Thus, seeing successful pro-breastfeeding mothers' comments appears to have a positive effect on breastfeeding attitudes, intentions, and information credibility.

Tugwell (2019) explored the importance of breastfeeding selfies through thematic analysis of a detailed case study. It was argued that the posting of a breastfeeding selfie may help mothers to define a maternal sense of self. Positive acceptance of such imagery may enhance the confidence of mothers. However, the author notes that this may not translate into confident breastfeeding behaviours. 


\section{Online community experiences.}

Four studies specifically focused on Facebook group dynamics. Bridges (2016) explored Facebook group experiences by interviewing members and administrators from three closed Facebook groups affiliated with the Australian Breastfeeding Association (ABA). Thematic analysis identified a major theme of support, and four sub-themes. The safe environment of the group was an important feature ('Community'). Benefits of immediacy ("Immediate”) and education ("Information") were also notable, however participants discussed the 'Complementary' nature of the online groups as a temporary replacement for offline groups. Bridges et al. (2018a) analysed the content of 15 closed Facebook groups that were affiliated to the ABA. The research identified that $44 \%$ of wall post queries were breastfeeding questions, covering a wide variety of topics. Posts demonstrated a need for support and reassurance, which appeared to be fulfilled. Posters used the group to establish social norms and validate choices. The paper concludes that discussed content itself is not as important as building a community and enhancing social norms within this.

Bridges et al. (2018b) furthers this by analysing ABA Facebook content by type. Facebook wall posts were largely emotional. A breakdown of queries $(n=165)$ found that $64 \%$ posted 'informational and emotional' queries, whereas $36 \%$ posted 'informational' queries. For shares $(n=613), 40 \%$ were categorised as 'informational' and $60 \%$ were categorised as 'informational and emotional'. The comment responses $(n=718)$ included 15\% 'informational', $16 \%$ 'emotional', and 69\% 'mixed'. The study emphasises the supportive nature of the community above the basic transmission of information.

Robinson et al. (2019) explore the experiences of Facebook support groups by AfricanAmerican mothers through online focus groups. The paper concludes that this environment is a 
beneficial support avenue that positively impacts upon breastfeeding duration. Specifically, Facebook communities are said to increase pro-breastfeeding norms, which impact upon confidence.

\section{Discussion}

The literature suggests that breastfeeding mothers appear to value social media as a facilitator of breastfeeding information (Alianmoghaddam et al., 2019; Bridges, 2016; GuerraReyes et al, 2016; Kallem et al., 2018; Majee et al., 2017; Thepha et al., 2018) and support (Asiodu et al., 2015; Bridges et al., 2018a; Bridges et al., 2018b; Guerra-Reyes et al, 2016; Hauck et al., 2016; Robinson et al., 2019; Thepha et al., 2018). However, this does not always appear to translate into positive breastfeeding outcomes (Asiodu et al., 2015; Niela-Vilén et al., 2016). While there is much more work to be completed in this area, several commonalities can be found across the key findings within the papers. These will be discussed below, alongside practical recommendations implied by the results.

The RCTs (Cavalcanti et al, 2019; Niela-Vilén et al., 2016) provide the most direct measure of the effectiveness of social media as an intervention for improving breastfeeding behaviours. Niela-Vilén et al., (2016) found no effect on breastfeeding rates when comparing the experimental group (access to a dedicated Facebook community) and control group, despite peer support group users preferring group support over midwife support. However, Cavalcanti et al, (2019) found their Facebook community resulted in a positive significant difference when compared to the control group. This difference may be partly due to low engagement within the study by Niela-Vilén et al. (2016). Approximately half of participants were passive in their usage. Furthermore, nine out of the remaining 40 participants assigned to the intervention group 
had not joined the Facebook community by the end of the study. In addition, content within Cavalcanti et al. (2019) appeared to be more regimented through the use of a schedule and tagged posts. It appears that social media has the potential to help breastfeeding practices, but content and set up needs thorough consideration to promote engagement.

Jin et al. (2015) was the only study to explicitly measure the impact of content manipulations on breastfeeding outcomes. The paper found that content credibility appeared to be of importance. Highly popular content (i.e. increased 'likes') had a stronger impact upon breastfeeding outcomes. This echoes cyberpsychological literature, which has identified a 'crowd effect' on news content, where increased likes translate to trust (Wang \& Mark, 2016). From this it is therefore recommended that breastfeeding associations spend time in building the popularity of their pages. The importance of credibility and trustworthiness was echoed across the research (Bahkali et al., 2015; Biediger-Friedman et al., 2018; Robinson et al., 2019). Mothers were more likely to trust and benefit from platforms that they perceive to be evidence-based or credible. Many of the studies also focused on pro-breastfeeding specific communities; general infant feeding and baby groups may lead to further inaccuracies. This aside, Guerra-Reyes et al. (2016) argue that mothers actively assess trustworthiness. Furthermore, Bridges et al. (2018b) emphasises that Facebook community group members appear to be good at recognising their own strengths and limitations and will often make their expertise level explicit. In order to ensure a sense of credibility, 'group rules' may want to emphasise that individuals providing support should state their level of expertise and acknowledge any uncertainties. As a suggestion, social media page administrators may find it useful to award badges of recognition to long-standing members who have been recognised for providing accurate support, assuring a level of credibility for those seeking advice. This is also supported within wider health psychology. For 
instance, research into drinking behaviours found that messages were better received from credible peers (Niu, Jeong \& Willoughby, 2020). It is also suggested that any shareable content should be branded to enhance credibility. Where possible, it may be worth providing links to any evidence-based blogs, or easily accessible peer-reviewed information within the description of the graphic to enhance the credibility of this information. This will also enhance source credibility, which has previously been linked to persuasion and attitude change (Hovland \& Weiss, 1951).

Jin et al. (2015) also identified that success testimonies elicit a more positive effect on breastfeeding outcomes and should therefore be encouraged. Therefore, it is implied that content should be monitored closely so that positive content is prioritised over negative content. It may be fruitful to use hashtag trends to promote positivity; and it may be particularly useful for those new to breastfeeding to see how issues can be overcome successfully. However, it should be noted that censorship of unsuccessful breastfeeding journeys is not advocated. Breastfeeding mothers within Robinson et al. (2019) noted that negativity towards other members could dissuade commenters from posting. It is suggested that efforts should be made to minimise the impact of any harmful content (such as misinformation) by gently correcting information and shutting down comments rather than promoting further discussion, which may draw attention. However, future research is needed to explore this suggestion further.

Although it was not experimentally tested, several other studies provided implications of content. For instance, research into usage patterns support the need to target information differently between the antenatal and postnatal period (Alianmoghaddam et al., 2019; Asiodu et al., 2015; Guerra-Reyes et al., 2016). The antenatal stage appears to rely more so on apps and readings, whilst postnatal social media usage may be more limited on time, and specifically 
focus on direct support. However, Asiodu et al. (2015) specifically suggests that key messages around breastfeeding (e.g. breast anatomy and physiology, and the importance of social support) are disseminated both antenatally and postnatally, but this is unsubstantiated from the data in their study. Three studies specifically highlighted the need for more diverse online role models to build self-efficacy (Asiodu et al., 2015; Hauck et al., 2016; Robinson et al., 2019). Furthermore, Marcon et al. (2019) noted that $77 \%$ of people captured within Instagram breastfeeding content were white. Taken together, the results suggest that wider representation would be valued. Content should not just be culturally diverse (as above), but also situationally diverse (i.e. age of mother and child, family dynamics, and the presence of visual disabilities). Those running breastfeeding support pages and groups within social media should make a conscious effort to diversify their content. The sharing of breastfeeding selfies (i.e. brelfies) within online communities may be useful in this regard. Although generalisability is an issue, Tugwell (2019)'s single participant case study of brelfies would support this.

The differences between the RCT results (Niela-Vilén et al., 2016; Cavalcanti et al., 2019) may emphasise the importance of building community dynamics. Given the low visiting rate reported within Niela-Vilén et al., (2016) it appears that a sense of community was not established, which may be due to the contrived nature of the group's initiation and assembly by the hospital. Facebook communities were the most studied environment across papers. Results found that online communities can successfully replace offline groups if face-to-face participation is difficult (Bridges, 2006; Cueva et al., 2017). However, studies also found that such avenues should ideally be temporary and only be supplementary to in-person support (Bridges, 2006; Cueva et al., 2017; Gallegos et al., 2011). In practice, it may be beneficial to link local breastfeeding groups with social media groups to help build the online community and 
encourage offline support. However, online groups should ensure that breastfeeding counsellors are available to ensure accuracy of information given that this appears to be the only method of support for some people (Bridges et al., 2018b).

Research surrounding Facebook communities were generally positive. Breastfeeding mothers appear to value the cyberpsychological affordances offered by social media. Studies discuss the benefit of around the clock accessibility, allowing support to be given in a timely manner (Bridges, 2016; Bridges et al., 2018b; Hauck et al., 2016; Robinson et al.; 2019). This may provide motivation to continue through difficult times (Biediger-Friedman et al., 2018). Furthermore, several papers discuss the importance of having a safe space and control over communications (Gallegos et al. 2011; Hauck et al., 2016). The connection with like-minded individuals seems to provide a catalyst for this, providing comfort and social norm reinforcement (Alianmoghaddam et al., 2019; Bridges, 2016; Cueva et al. 2017). This could link to the cyberpsychological 'echo chamber effect', where social media users tend to have their opinion echoed back due to following those with similar thoughts (Quattrociocchi, Scala \& Sunstein, 2016). This echo effect may help to normalise their viewpoint, which may be particularly important for individuals with no offline breastfeeding support. Indeed Tugwell (2019) argues that like-mindedness removes women away from the negative discourses surrounding breastfeeding found external to these safe places. Previous research has already highlighted societal negativity as a deterrent to breastfeeding (Dowling \& Brown, 2013). Thus research may imply that pro-breastfeeding groups should be promoted over general infant feeding groups.

Community strength may also be reliant on the community's evolution. Five studies (Alianmoghaddam, et al., 2019; Bridges, 2016; Bridges et al., 2018b; Hauck et al., 2016; Robinson et al., 2019) identified community development as an important feature of success, 
whereby individuals within the communities adopt a reciprocal supportive role to continue helping others and maintain group momentum. Furthermore, this sharing of knowledge may act as a protector of misinformation by ensuring that correct and useful knowledge is recycled within the evolution of the group. From this, it is suggested that groups may want to consider mentorship schemes, whereby experienced 'moderators' recruit long-standing community members and encourage them to share their experiences. This will help the group's sustainability as well as providing mothers' testimonies for others to read, as advocated by Jin et al. (2015). Furthermore, mentoring could potentially have a knock-on effect for increasing breastfeeding awareness outside of the breastfeeding community (Robinson et al., 2019).

Finally, social media success may depend on demographics. Hauck identified crosscultural differences when assigning importance to online support. While Irish participants held social media in the highest regard compared to other countries, UNICEF (2019) note that Ireland has the worst breastfeeding rates worldwide. Thus online support may be particularly important for populations that struggle to maintain breastfeeding rates despite initiation. Furthermore, Thepha, et al. (2018) noted that online support use appeared to be more salient for those within urban areas as opposed to peri-urban areas, and for those with further education, potentially due to the digital divide in terms of technology access.

\section{Theory of Planned Behaviour}

In the introduction it was suggested that Ajzen's (1985) Theory of Planned Behaviour could provide a theoretical lens to explore how social media may impact upon breastfeeding practice by increasing a mother's intention to breastfeed. From the narrative synthesis assumptions can be made on how various elements of social media can perhaps be applied to 
positively impact the three key elements of this model: attitudes, subjective norms, and perceived behavioural control.

Social media may have the ability to increase positive attitudes towards breastfeeding through the sharing of information. Studies such as Bahkali et al. (2015), suggest that regular positive messages surrounding breastfeeding as a positive health behaviour may have the potential to increase breastfeeding awareness and fuel positive attitudes. The Elaboration Likelihood Model (ELM; Petty \& Cacioppo, 1986) suggests that individuals are more likely to pay attention to such messages if they relate to the source. Social media algorithms have the potential to increase levels of personalisation when distributing information, through, for example, targeted adverts. Furthermore, numerous studies have highlighted how social media communities can act as a safe space due to shared norms. Indeed, a participant within GuerraReyes, et al (2016) commented that a lot of breastfeeding information is 'unspoken of'. Social media allows access to other women with these 'hidden' experiences, providing a sense of normality. Such communities appear to validate breastfeeding behaviours, reinforcing a probreastfeeding norm (Bridges, 2018a). The reassurance and support from others may also boost confidence (Robinson et al., 2019). Furthermore, the viewing of similar role models through visual content (Tugwell, 2019) or success stories (Jin et al., 2015) also appears to have an effect on self-efficacy. Social media may also reduce traditional barriers to accessing offline breastfeeding support such as childcare and transport (Bridges, 2016; Cueva et al., 2017), further increasing the individual's perceived behavioural control.

The model demonstrates that social media holds good potential as a facilitator for breastfeeding behaviours, but it is also warned that many of the studies specifically evaluate probreastfeeding environments. For instance, breastfeeding related hashtags were found to be 
predominately positive (Marcon et al. 2019). While this is encouraging, it may only be beneficial to those deliberately seeking out pro-breastfeeding environments and communities, such as those with an existing intention to breastfeed.

\section{Future Research and Limitations}

Gallegos et al. (2011) argue that a general recommendation of breastfeeding from an expert opinion may have the potential to foster in-group/out-group dynamics. This division is potentially reinforced within social media. Social media emphasises polarised viewpoints through aforementioned 'echo chambers' (Quattrociocchi et al., 2016), whereby users follow others with similar viewpoints, which in turn reinforces their point of view. These fundamental social psychology dynamics hold high importance, given reports that mothers can feel shamed by breastfeeding promotion (Donnelly, 2018). Thus, breastfeeding information needs to be informative and accurate without being disrespectful to those who choose not to, or feel that they could not, breastfeed. More research needs to be conducted on specific content, such as infographics and hashtags, to understand not only their impact upon breastfeeding outcomes, but also the perceptions of such content by non-breastfeeding individuals.

A number of negative elements of social media were touched upon from the research, but not explored further. For instance, Robinson et al. (2019) noted that online spaces may provide a false sense of security in regards to perceived confidentiality. More research is needed in regard to online safety of breastfeeding communities. Furthermore, in their general exploration of facilitators to exclusive breastfeeding, Thepha et al. (2018) identified the advertisement of artificial milk in public media as a barrier. Although this was discussed in general it could 
perhaps be applied to social media, given that targeted algorithms may promote the unwanted occurrence of artificial milk pages within individual feeds. Furthermore, incentives from 'baby clubs' entice users to subscribe to Facebook pages dedicated to artificial milk, which may make this type of advertising more prominent. Future research should look into the effects of artificial milk promotion through social media. This should also include researching the indirect advertising of artificial milk by social media influencers.

This review relies on papers identified via a database search strategy and therefore may miss out relevant grey literature, or papers that fall outside of the search criteria. Future research should also build on the limitations of the included studies. For instance, more specific participant information will help aid analysis. Where longitudinal studies are conducted, it would be useful to identify those who go on to breastfeed exclusively separately from those who do not. By providing more information about the parent-child feeding journey, more emphasis could then be placed on the things that successful mothers find helpful. There were several general limitations to the included studies that should be noted. First, most papers focused on the postnatal period. Indeed, none of the studies focused solely on pregnant women in the antenatal period. It is important to acknowledge that more research needs to be completed with these women. Furthermore, as Table 1 suggests, most of the studies either focused on social media generally or Facebook communities specifically. Research into newer social media is minimal. Finally, many of the studies focused on breastfeeding in infants only, though there were exceptions (for instance, Majee et al, 2017 noted that 14 participants were feeding past 6 months). Perhaps the key limitation of this review is that the perceptions of mothers who did not breastfeed but wanted to is largely under-represented in the literature, yet could play a pivotal role in understanding the limitations and disadvantages of social media. Indeed Asiodu et al. 
(2015) found that Facebook support is perceived differently between those who combination feed, and those who exclusively breastfeed. Well-meaning advice may undermine the breastfeeding journey of another user if it is based around incorrect or unsupportive information. As an example, the hashtag 'fedisbest' is often shared as a mechanism to help protect mothers from feeling the negative emotions associated with stopping breastfeeding against their will (such as guilt and shame - Mozingo, Davis, Droppleman, \& Merideth, 2000). However, this could perpetuate a circle of misinformed support, which may encourage a mother to view their breastfeeding journey as futile. Future research should aim to focus on those who are in this particular demographic, to ensure content is sensitive enough so it is not detrimental to the wellbeing of any mother, whilst maintaining the aim of improved support and accurate information to those who do wish to breastfeed.

\section{Conclusion}

Social media has the potential to improve breastfeeding attitudes and knowledge. Private support groups encourage mothers to be open and disinhibited about their support needs, whilst online community strength allows for supplementary support. Community evolution may play a role in individual identity, allowing a natural progression of self-actualisation through supporting others. Members have the potential to become role models for their wider community. It is hoped that the recommendations within this review will help to encourage more positive and supportive content within social media platforms. 


\section{References}

Alianmoghaddam, N., Phibbs, S., \& Benn, C. (2019). "I did a lot of googling": a qualitative study of exclusive breastfeeding support through social media. Women and Birth, 32(2), 147156.

Asiodu, I.V., Waters, C.M., Dailey, D.E., Lee, K.A., \& Lyndon, A. (2015). Breastfeeding and the use of Social Media Among First-Time African American Mothers. Journal of Obstetric, Gynecologic, \& Neonatal Nursing, 44(2), 268-278.

Ajzen, I. (1985). From intentions to actions: A theory of planned behavior. In J. Kuhi \& J. Beckmann (Eds.), Actionócontrol: From cognition to behavior (pp. 11ó39). Heidelberg: Springer.

Bahkali, S., Alkharjy, N., Alowairdy, M., Househ, M., Da’ar, O., \& Alsurimi, K. (2015). A Social Media Campaign to Promote Breastfeeding among Saudi Women: A Web-based Survey Study. Enabling Health Informatics Applications, 213, 247-50.

Biediger-Friedman, L., Silva, M., \& Smith, K. (2018). A Focus Group Study Observing Maternal Intention to Use a WIC Education App. American Journal of Health Behavior, 42(6),110-123.

Bridges, N. (2016). The faces of breastfeeding support: Experiences of mothers seeking breastfeeding support online. Breastfeeding Review, 24(1), 11.

Bridges, N., Howell, G., \& Schmied, V. (2018a). Exploring breastfeeding support on social media. International Breastfeeding Journal, 13(22).

Bridges, N., Howell, G., \& Schmied, V. (2018b). Breastfeeding peer support on social networking sites. Breastfeeding Review, 26(2), 17. 
Cavalcanti, D. S., Cabral, C. S., de Toledo Vianna, R. P., \& Osório, M. M. (2019). Online participatory intervention to promote and support exclusive breastfeeding: Randomized clinical trial. Maternal \& child nutrition, 15(3), e12806.

Cleminson, J., Oddie, S., Renfrew, M.J., McGuire, W. (2015). Being baby friendly: evidencebased breastfeeding Support. Archives of Disease in Childhood: Fetal and Neonatal Edition, 100, F173-F178.

Cross-Barnet, C., Augustyn, M., Gross, S., Resnik, A., \& Paige, D. (2012). Long-term breastfeeding support: failing mothers in need. Maternal and child health journal, 16(9), 19261932.

Cueva, K., Shimer, S., Kent, D., Geller, A.C., Viswanath, K., \& Fung, T.T. (2017). Strengths and Challenges of the Alaska WIC Breastfeeding Peer Counselor Program: A Qualitative Study of Program Implementation. Journal of Nutrition Education and Behavior, 49(10), 858-866.

Donnelly, L. (2018). New mothers should not be shamed into breastfeeding. Telegraph. https://www.telegraph.co.uk/news/2018/06/11/new-mothers-should-not-shamed-breastfeeding/

Dowling, S., \& Brown, A. (2013). An exploration of the experiences of mothers who breastfeed long-term: what are the issues and why does it matter?. Breastfeeding Medicine, 8(1), 45-52.

Gallegos, D., Russell-Bennett, R., \& Previte, J. (2011). An innovative approach to reducing risks associated with infant feeding: the use of technology. Journal of Nonprofit and Public Sector Marketing, 23(4), 327-347. 
Guerra-Reyes, L., Christie, V.M., Prabhakar, A., Harris, A.L., \& Siek, K.A. (2016). Postpartum Health Information Seeking Using Mobile Phones: Experiences of Low-Income Mothers. Maternal Child Health Journal, 20(1), 13-21.

Hauck, Y.L., Blixt, I., Hildingsson, I., Gallagher, L., Rubertsson, C., Thomson, B., \& Lewis, L. (2016). Australian, Irish, and Swedish women's perceptions of what assisted them to breastfeed for six months: exploratory design using critical incident technique. BMC Public Health, 16(1), 1067.

Hovland, C. I., \& Weiss, W. (1951). The influence of source credibility on communication effectiveness. Public opinion quarterly, 15(4), 635-650.

Jin, S.V., Phua, J., \& Lee, K. M. (2015). Telling stories about breastfeeding through Facebook: The impact of user-generated content (UGC) on pro-breastfeeding attitudes. Computers in Human Behavior, 46, 6-17.

Kallem, S., Gruver, R. S., Virudachalam, S., \& Fiks, A. G. (2018). Mothers’ Facebook posts about infant health: findings from the Grow2Gether study. BMC Pediatrics, 18, 341-348.

Khan, K. S., Kunz, R., Kleijnen, J., \&Antes, G. (2003). Five steps to conducting a systematic review. Journal of the Royal Society of Medicine, 96, 118-121. doi:

$10.1177 / 014107680309600304$

Kmet, L. M., Lee, R.C. \& Cook, L. S. (2004). Standard quality assessment criteria for evaluating primary 2 research papers from a variety of fields. Edmonton, Alta: Alberta Heritage Foundation for 3 Medical Research. 
Korda, H. \& Itani, Z. (2013). Harnessing Social Media for Health Promotion and Behavior Change. Health Promotion Practice, 14(1), 15-23.

Lee, K., Vasileiou, K. \& Barnett, J. (2017). 'Lonely within the mother': An exploratory study of first-time mothers' experiences of loneliness. Journal of Health Psychology, 24(10), 1334-1344.

Majee, W., Thullen, M. J., Davis, A. N., \& Sethi, T. K. (2017). Influences on infant feeding: Perceptions of mother-father parent dyads. MCN: The American Journal of Maternal/Child Nursing, 42(5), 289-294.

Marcon, A. R., Bieber, M., \& Azad, M. B. (2019). Protecting, promoting, and supporting breastfeeding on Instagram. Maternal \& child nutrition, 15(1), e12658.

McAndrew, F., Thompson, J., Fellows, L., Large, A., Speed, M., \& Renfrew, M. J. (2012). Infant feeding survey 2010. Leeds: Health and Social Care Information Centre. Available at: https://files.digital.nhs.uk/publicationimport/pub08xxx/pub08694/infant-feeding-survey-2010$\underline{\text { consolidated-report.pdf }}$

Moher, D., Liberati, A., Tetzlaff, J., \& Altman, D. G. (2009). Preferred reporting items for systematic reviews and meta-analyses: the PRISMA statement. Annals of internal medicine, 151(4), 264-269.

Mozingo, J. N., Davis, M. W., Droppleman, P. G., \& Merideth, A. (2000). "It Wasn't Working": Women's Experiences with Short-Term Breastfeeding. MCN: The American Journal of Maternal/Child Nursing, 25(3), 120-126. 
Niela-Vilén, H., Axelin, A., Melender, H.L., Löyttyniemi, E., \& Salanterä, S. (2016).

Breastfeeding preterm infants - A randomized controlled trial of the effectiveness of an Internetbased peer-support group. Journal of Advanced Nursing, 72(10), 2495-507.

Orchard, L.J. (2019). Uses and gratifications of social media: Who uses it and why? In A. AttrillSmith, C. Fullwood, M. Keep, \& D. J. Kuss (Eds.) The Oxford Handbook of Cyberpsychology, Oxford: Oxford University Press.

Petty, R. E., \& Cacioppo, J. T. (2012). Communication and persuasion: Central and peripheral routes to attitude change. Springer Science \& Business Media.

Quattrociocchi, W., Scala, A., \& Sunstein, C. R. (2016). Echo chambers on Facebook. Available at $\operatorname{SSRN} 2795110$.

Renfrew, M.J., Pokhrel, S., Quigley, M., McCormick, F., Fox-Rushby, J., Dodds, R.,... Williams, A. (2012) Preventing disease and saving resources: the potential contribution of increasing breastfeeding rates in the UK. Unicef Report. Available at: https://www.unicef.org.uk/wpcontent/uploads/sites/2/2012/11/Preventing_disease_saving_resources.pdf

Robinson, A., Davis, M., Hall, J., Lauckner, C., \& Anderson, A. K. (2019). It takes an e-village: Supporting African American mothers in sustaining breastfeeding through Facebook communities. Journal of Human Lactation, 0890334419831652.

Rollins, N.C., Bhandari, N., Hajeebhoy, N., Horton, S., Lutter, C.K., Martines, J.C.,... Victora, C.G.; on behalf of the Lancet Breastfeeding Series Group. (2016). Why invest, and what it will take to improve breastfeeding practices? Lancet, 387, 491-504. 
Royal College of Paediatrics and Child Health (2019). Breastfeeding in the UK-Position statement. https://www.rcpch.ac.uk/resources/position-statement-breastfeeding-uk

Stuebe, A. (2009). The Risks of Not Breastfeeding for Mothers and Infants. Reviews in Obstetrics and Gynecology, 2(4), 222-231.

Thepha, T., Marais, D., Bell, J., \& Muangpin, S. (2018). Perceptions of northeast Thai breastfeeding mothers regarding facilitators and barriers to six- month exclusive breastfeeding: focus group discussions. International Breastfeeding Journal, 13(14).

Thomas, J., \& Harden, A. (2008). Methods for the thematic synthesis of qualitative research in systematic reviews. BMC medical research methodology, 8(1), 45 .

Tomfohrde, O.J., \& Reinke, J.S. (2016). Breastfeeding mothers' use of technology while breastfeeding. Computers in Human Behavior, 64, 556-561.

Tugwell, S. (2019). Breastfeeding selfies as relational practice: becoming a maternal subject in the digital age: a single case study. International Breastfeeding Journal, 14, 23.

UNICEF (2016). Breastfeeding and the Sustainable Development Goals: Factsheet. Available at: https://worldbreastfeedingweek.org/2016/pdf/BreastfeedingandSDGsMessaging\%20WBW2016 \%20Shared.pdf

UNICEF (2019). Wealthiest countries have lowest breastfeeding rates - including Ireland. Available at: https://www.unicef.ie/2019/08/01/family-friendly-policies-increase-breastfeedingrates-worldwide/

Wang, Y., \& Mark, G. (2016). News trustworthiness and verification in China: The tension of dual media channels. First Monday. 
West, J., Hall, C. P., Hanson, C., Thackeray, R., Barnes, M., Neiger, B., \& McIntyre, E. (2011). Breastfeeding and blogging: Exploring the utility of blogs to promote breastfeeding. American Journal of Health Education, 42(2), 106-115.

World Health Organization (2015). WHO European region has lowest global breastfeeding rates. Available at: https://www.euro.who.int/en/health-topics/Life-stages/maternal-and-newbornhealth/news/news/2015/08/who-european-region-has-lowest-global-breastfeeding-rates

World Health Organization (2018). Infant and young child feeding. Available at https://www.who.int/en/news-room/fact-sheets/detail/infant-and-young-child-feeding

Xu, W.W., Chiu, I., Chen, Y., \& Mukherjee, T. (2015). Twitter hashtags for health: applying network and content analyses to understand the health knowledge sharing in a Twitter-based community of practice. Quality and Quantity, 49(4), 1361-1380.

\title{
Supporting Information
}

\author{
Search Strategy
}

S1: breastfe*

S2: breast fe*

S3: infant fe*

S4: human milk

S5: breast milk

S6: lactat*

S7: latch 
S8: S1 OR S2 OR S3 OR S4 OR S5 OR S6 OR S7

S9:social media

S10:facebook

S11:twitter

S12:brelfie

S13:social network* site*

S14: SNS*

S15: instagram

S16: pinterest

S17: youtube

S18: meme*

S19: cyber*

S20: smartphone

S21: cell phones

S22: emoji*

S23: app

S24: apps

S25: mobile

S26: mobile applications

S27: blog*

S28: web 2.0 
S29: user generated content

S30: UGC

S31: S9 OR S10 OR S11 OR S12 OR S13 OR S14 OR S15 OR S16 OR S17 OR S18 OR S19

OR S20 OR S21 OR S22 OR S23 OR S24 OR S25 OR S26 OR S27 OR S28 OR S29 OR S30

S32 - FINAL SEARCH: S8 AND S31

Limiters:

2007-

Peer-reviewed

English 
Tables

Table 1:

Extraction Table

\begin{tabular}{|c|c|c|}
\hline Study Characteristics & Participants & Analysis and Quality \\
\hline \multicolumn{3}{|l|}{ Quantitative Studies } \\
\hline $\begin{array}{l}\text { - } \text { Authors: Jin et al. (2015) } \\
\text { - Location: United States } \\
\text { - Study Aim: To examine the impact of content } \\
\text { style and valence, and online page popularity of a } \\
\text { pro-breastfeeding Facebook page on female } \\
\text { college students' breastfeeding outcomes. } \\
\text { - Design: Cross-sectional } \\
\text { - Platform: Facebook }\end{array}$ & $\begin{array}{l}\text { - Criteria: Undergraduate female students at } \\
\text { university with no breastfeeding } \\
\text { experience. } \\
\text { - } \\
\text { - } \\
\text { Checruitment: Email advert. } \\
\text { female), Mean }=19.82(\mathrm{SD}=1.472) \text {; } \\
\text { Study } 2: \mathrm{n}=294(100 \% \text { female }), \text { Mean }= \\
20.32(\mathrm{SD}=2.12) .\end{array}$ & $\begin{array}{ll} & \text { Series of ANOVAs. } \\
- & 1.00\end{array}$ \\
\hline $\begin{array}{l}\text { - } \text { Authors: Niela-Vilén et al. (2016) } \\
\text { - Location: Finland } \\
\text { - Study Aim: To examine whether an Internet- } \\
\text { based peer support intervention had an effect on } \\
\text { the duration of breastfeeding, breast milk } \\
\text { expression or maternal breastfeeding attitude, } \\
\text { compared with routine care in the mothers of } \\
\text { preterm infants. } \\
\text { - Design: RCT; Longitudinal } \\
\text { - Platform: Facebook }\end{array}$ & $\begin{array}{l}\text { Criteria: Mothers of preterm infants in } \\
\text { first week postpartum. } \\
\text { Recruitment: Mothers fitting criteria } \\
\text { approached. } \\
\text { Characteristics: } n=124(100 \% \text { female }) \text {; } \\
\text { Experimental: } n=60, \text { Median age }=29 \\
\text { years; Control: } n=64, \text { Median age }=31 \text {. }\end{array}$ & $\begin{array}{l}\text { - Chi-square } \\
\text { tests/Fisher's exact } \\
\text { test; two-samples t- } \\
\text { test/Mann-Whitney } \\
\text { U-test; Correlation. } \\
\text { Cox's proportional } \\
\text { hazard model. } \\
0.96\end{array}$ \\
\hline
\end{tabular}




\begin{tabular}{|c|c|c|}
\hline Study Characteristics & Participants & Analysis and Quality \\
\hline $\begin{array}{l}\text { - } \text { Authors: West et al. (2011) } \\
\text { - Location: United States } \\
\text { - Study Aim: To explore the usefulness of blogs in } \\
\text { - } \text { the support of breastfeeding behaviour. } \\
\text { - Pesign: Cross-sectional } \\
\text { - }\end{array}$ & $\begin{array}{l}\text { - Criteria: Blogs with 'breastfeed/ing' in } \\
\text { the title or URL. } \\
\text { Recruitment: Identified } 425 \text { blogs. } \\
\text { Following manual searches } 32 \text { blogs } \\
\text { remained. Computerised random sample. } \\
\text { - Characteristics: } 354 \text { posts and } 881 \\
\text { comments. }\end{array}$ & $\begin{array}{ll} & \text { Content analysis; } \\
& \text { ANOVAs. } \\
\text { - } & 0.86\end{array}$ \\
\hline $\begin{array}{l}\text { - Authors: Cavalcanti et al. (2018) } \\
\text { - Location: Brazil } \\
\text { - Study Aim: To assess the impact on breastfeeding } \\
\text { of a participatory intervention using an online } \\
\text { social network. } \\
\text { - Design: RCT; Longitudinal: Monthly up to six } \\
\text { months postpartum. } \\
\text { - Platform: Facebook }\end{array}$ & $\begin{array}{l}\text { Criteria: Gave birth during research } \\
\text { period, over 18years, literate, Facebook } \\
\text { users. Excluded: mothers distanced from } \\
\text { child, illness that contraindicated } \\
\text { breastfeeding, premature infant, multiple } \\
\text { births, congenital issue affecting } \\
\text { breastfeeding. } \\
\text { - Recruitment: Specific maternity ward in } \\
\text { Brazil. } \\
\text { - Characteristics: } \mathrm{n}=251 \text { (100\% female); } \\
\text { Intervention: } \mathrm{n}=123 \text {, Control: } \mathrm{n}=128 ; 78 \% \\
\text { of intervention group and } 77.3 \% \text { of } \\
\text { control group were between } 20 \text { and } 34 \\
\text { years. }\end{array}$ & $\begin{array}{l}\text { - Chi-square test; } \\
\text { Survival analysis } \\
\text { using Kaplan-Meier } \\
\text { technique; Log rank } \\
\text { test; Cox regression } \\
\text { model } \\
\text { - } 0.85\end{array}$ \\
\hline $\begin{array}{l}\text { - Authors: Bridges et al. (2018b) } \\
\text { - Location: Australia } \\
\text { - Study Aim: To explore breastfeeding peer support } \\
\text { via closed Facebook groups facilitated by the } \\
\text { Australian Breastfeeding Association (ABA). } \\
\text { - Design: Cross-sectional } \\
\text { - Platform: Facebook }\end{array}$ & $\begin{array}{l}\text { - Criteria: Captured wall posts and } \\
\text { comments of } 15 \text { closed Facebook groups } \\
\text { over a 4-weeek period. } \\
\text { - Recruitment: Online invitation sent via } \\
\text { ABA email and Facebook. } \\
\text { - Characteristics: NR }\end{array}$ & $\begin{array}{l}\text { - Online ethnographic } \\
\text { content analysis. } \\
\text { - } 0.68\end{array}$ \\
\hline
\end{tabular}




\begin{tabular}{|c|c|c|}
\hline Study Characteristics & Participants & Analysis and Quality \\
\hline $\begin{array}{l}\text { - } \text { Authors: Bahkali et al. (2015) } \\
\text { - Location: Saudi Arabia } \\
\text { - Study Aim: To evaluate the impact of a Twitter- } \\
\text { based education campaign to promote } \\
\text { breastfeeding. } \\
\text { - } \text { Design: Cross-sectional } \\
\text { - Platform: Twitter }\end{array}$ & $\begin{array}{l}\text { - Criteria: Existing followers of a women's } \\
\text { health campaign Twitter account. } \\
\text { - Recruitment: Twitter account. } \\
\text { - Characteristics: } \mathrm{n}=484 \text { (assumed } 100 \% \\
\text { female but NR explicitly); 15-24 years } \\
\mathrm{n}=120 ; 25-34 \text { years } \mathrm{n}=161 ; 35-44 \text { years } \\
\mathrm{n}=112 \text {. }\end{array}$ & $\begin{array}{ll}\text { - } & \text { Percentages. } \\
\text { - } & 0.67\end{array}$ \\
\hline $\begin{array}{l}\text { - } \text { Authors: Tomfohdre et al. (2017) } \\
\text { - Location: United States } \\
\text { - Study Aim: To explore the social media habits of } \\
\text { breastfeeding mothers while they are } \\
\text { breastfeeding. } \\
\text { - } \quad \text { Design: Cross-sectional } \\
\text { - Platform: Facebook, Pinterest, Twitter, Instagram }\end{array}$ & $\begin{array}{l}\text { - Criteria: Currently nursing, or had in the } \\
\text { past } 5 \text { years; } 18 \text { years plus. } \\
\text { Recruitment: Recruitment via social } \\
\text { media and personal connections. } \\
\text { Characteristics: } n=309 \text { (100\% female); } \\
\text { Range }=26-30 \text { years. }\end{array}$ & $\begin{array}{ll}\text { - } & \text { Percentages } \\
\text { - } & 0.39\end{array}$ \\
\hline
\end{tabular}

\section{Qualitative Studies}

- Authors: Robinson et al. (2019)

- Location: United States

- Study Aim: To examine experiences of African American mothers who use breastfeeding support communities in Facebook.

- Design: Cross-sectional.

- Platform: Facebook
- Criteria: First-time, self-identifying

African-American mothers, 18 years plus, breastfeeding at data collection, participating in a breastfeeding Facebook group.

- Recruitment: Facebook group advertising. Stratified, purposive sampling for a diverse sample.

- Characteristics: $\mathrm{n}=22$ (100\% female); Mean age $=30$ years $(\mathrm{SD}=4.9)$ 


\begin{tabular}{|c|c|c|}
\hline Study Characteristics & Participants & Analysis and Quality \\
\hline $\begin{array}{l}\text { - Authors: Bridges (2016) } \\
\text { - Location: Australia } \\
\text { - Study Aim: To understand experiences of mothers } \\
\text { using closed Facebook groups (Australian } \\
\text { Breastfeeding Association, ABA approved) and } \\
\text { how these mothers find and share breastfeeding } \\
\text { support in this platform. } \\
\text { - Design: Cross-sectional. } \\
\text { - Platform: Facebook }\end{array}$ & $\begin{array}{l}\text { - } \text { Criteria: NR. } \\
\text { Recruitment: Recruitment call via ABA } \\
\text { email and Facebook channels. Three out } \\
\text { of potential } 17 \text { groups chosen. } \\
\text { - Characteristics: Administrators and group } \\
\text { participants. N=23 (100\% female) }\end{array}$ & $\begin{array}{ll}\text { - } & \text { Thematic analysis. } \\
\text { - } & 0.95\end{array}$ \\
\hline $\begin{array}{l}\text { - } \text { Authors: Asiodu et al. (2015) } \\
\text { - Location: United States } \\
\text { - Study Aim: To explore the use of social media } \\
\text { during antepartum and postpartum periods among } \\
\text { first-time African American mothers and their } \\
\text { support persons. } \\
\text { - Design: Ethnographic; Longitudinal: during } \\
\text { - Platfortum and postpartum periods. } \\
\text { - Pacebook }\end{array}$ & $\begin{array}{l}\text { Criteria: English-speaking, self-identified } \\
\text { African American first-time mothers. } \\
\text { Aged } 18 \text { years plus. } \\
\text { Recruitment: Recruitment flyers in } \\
\text { hospitals, clinics and community-based } \\
\text { organisations. } \\
\text { Characteristics: Participant: } n=14(100 \%) \text {, } \\
\text { Median age }=23.5 \text { years; Range }=21-36 \text {; } \\
\text { Support persons: undisclosed. }\end{array}$ & $\begin{array}{l}\text { - Thematic analysis } \\
\text { informed by critical } \\
\text { ethnography, the } \\
\text { family life course } \\
\text { development theory, } \\
\text { and Black feminist } \\
\text { theory. } \\
0.90\end{array}$ \\
\hline $\begin{array}{l}\text { - } \text { Authors: Marcon et al. (2018) } \\
\text { - Location: Canada } \\
\text { - Study Aim: To explore if and how breastfeeding } \\
\text { - } \quad \text { is promoted and supported on Instagram. } \\
\text { - Pesign: Cross-sectional; Collected over one week. } \\
\text { Platform: Instagram }\end{array}$ & $\begin{array}{l}\text { - Criteria: Posts containing: \#breastfeeding, } \\
\text { \#breastmilk, \#breastisbest, } \\
\text { \#normalizebreastfeeding. } \\
\text { - Recruitment: Instagram search } \\
\text { - Characteristics: Captured } 4089 \text { images } \\
\text { with 20,532 comments. }\end{array}$ & $\begin{array}{ll} & \text { Content analysis. } \\
\text { - } & 0.85\end{array}$ \\
\hline
\end{tabular}




\begin{tabular}{|c|c|c|}
\hline Study Characteristics & Participants & Analysis and Quality \\
\hline $\begin{array}{l}\text { - Authors: Guerra-Reyes et al. (2016) } \\
\text { - Location: United States } \\
\text { - Study Aim: To assess low-income mothers' } \\
\text { perceptions of their information seeking } \\
\text { behaviour and their use of mobile technology to } \\
\text { address those needs. } \\
\text { - Design: Cross-sectional } \\
\text { - Platform: Facebook; Blogs }\end{array}$ & $\begin{array}{l}\text { - Criteria: Mothers must have lived in } \\
\text { Monroe County, with at least one child } \\
\text { under 4 years. } \\
\text { - } \\
\text { - } \\
\text { Characteritment: Community partnerships. } n=10(100 \% \text { female }) \\
\text { Mean }=29.9(S D=3.6)\end{array}$ & $\begin{array}{ll}\text { - } & \text { Content analysis. } \\
\text { - } & 0.85\end{array}$ \\
\hline $\begin{array}{l}\text { - Authors: Cueva et al. (2017) } \\
\text { - } \quad \text { Location: United States } \\
\text { breastfeeding peer counsellor (BFPC) program } \\
\text { with Alaska Special Supplemental Nutrition } \\
\text { Program for Women, Infants, and Children } \\
\text { (WIC). } \\
\text { - Design: Cross-sectional } \\
\text { - Platform: Facebook }\end{array}$ & $\begin{array}{l}\text { - Criteria: Associated with BFPC. } \\
\text { Recruitment: Focus group: Peer } \\
\text { counsellors identified clients as potential } \\
\text { participants; Interviews: WIC BFPCs and } \\
\text { staff; Online surveys: Breastfeeding } \\
\text { clients across } 3 \text { WIC BFPC sites. } \\
\text { - Characteristics: Focus groups: } n=25 \\
\text { (100\% females); Interviews: } n=33 \text { (97\% } \\
\text { females); Survey: } n=129 \text { (100\% females) }\end{array}$ & $\begin{array}{ll}\text { - } & \text { Thematic analysis } \\
\text { - } & 0.85\end{array}$ \\
\hline $\begin{array}{l}\text { - } \quad \text { Authors: Bridges et al. (2018a) } \\
\text { - } \quad \text { Location: Australia } \\
\text { - Study Aim: To explore breastfeeding topics via } \\
\text { social networking sites, and how breastfeeding } \\
\text { peer supporters respond to such queries. } \\
\text { - } \quad \text { Design: Longitudinal; Over 4-week period. } \\
\text { - Platform: Facebook }\end{array}$ & 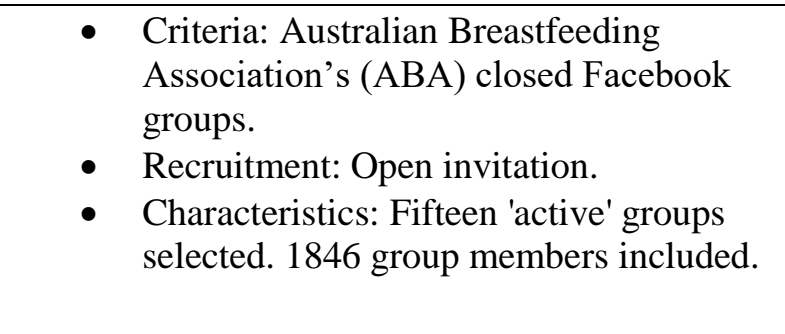 & $\begin{array}{ll}\text { - } & \text { Content analysis. } \\
\text { - } & 0.85\end{array}$ \\
\hline
\end{tabular}




\begin{tabular}{|c|c|c|}
\hline Study Characteristics & Participants & Analysis and Quality \\
\hline $\begin{array}{l}\text { - Authors: Hauck et al. (2016) } \\
\text { - Location: Australia } \\
\text { - Study Aim: To explore women's perceptions of } \\
\text { what assisted them to continue breastfeeding for } \\
\text { six months (cross-cultural). } \\
\text { - Design: Cross-sectional } \\
\text { - Platform: }\end{array}$ & $\begin{array}{l}\text { - Criteria: Women who breastfed for a } \\
\text { minimum of } 6 \text { months (in the past } 12 \\
\text { months or currently nursing). } \\
\text { - Recruitment: Advertisements in local } \\
\text { newspapers and on social media. } \\
\text { Characteristics: } \mathrm{n}=356(100 \% \text { female): } \\
\text { Australian: } \mathrm{n}=153 \text {, Mean age }=33.5(\mathrm{SD} \\
=4.92) \text {; Irish: } \mathrm{n}=64, \text { Mean age }=34.9 \\
(\mathrm{SD}=4.01) ; \text { Swedish: } \mathrm{n}=139 \text {, Mean age = } \\
33.5(\mathrm{SD}=5.61) \text {. }\end{array}$ & $\begin{array}{ll}\text { - } & \text { Content analysis. } \\
\text { - } & 0.80\end{array}$ \\
\hline $\begin{array}{l}\text { - } \text { Authors: Biediger-Friedman et al. (2018) } \\
\text { - Location: United States } \\
\text { - Study Aim: To explore technology acceptance of } \\
\text { a mobile application to facilitate healthy } \\
\text { behaviours. } \\
\text { - Design: Cross-sectional } \\
\text { - Platform: App with 'share' function; linked to } \\
\text { Facebook. }\end{array}$ & $\begin{array}{l}\text { - Criteria: Mothers with a smartphone data } \\
\text { plan from local communities. } \\
\text { - Recruitment: Recruited from WIC agents } \\
\text { in Texas. } \\
\text { - Characteristics: } n=48(100 \% \text { female }) ; 18- \\
28 \text { years } n=25 ; 29-40 \text { years } n=21 ; 41-47 \\
\text { years } n=2 \text {. }\end{array}$ & $\begin{array}{ll}\text { - } & \text { Thematic analysis. } \\
\text { - } & 0.80\end{array}$ \\
\hline $\begin{array}{l}\text { - } \text { Authors: Tugwell (2019) } \\
\text { - Location: United Kingdom } \\
\text { - Study Aim: To gain a better understanding of } \\
\text { breastfeeding selfies. } \\
\text { - Design: Case Study } \\
\text { - Platform: Facebook }\end{array}$ & $\begin{array}{l}\text { - Criteria: Share breastfeeding selfies. } \\
\text { - Recruitment: Recruited via closed } \\
\text { Facebook group for breastfeeding older } \\
\text { children. } \\
\text { - Characteristics: } \mathrm{n}=1 \text { (100\% female); Age } \\
=32 .\end{array}$ & $\begin{array}{ll} & \text { Thematic analysis. } \\
\text { - } & 0.75\end{array}$ \\
\hline
\end{tabular}




\begin{tabular}{|c|c|c|}
\hline Study Characteristics & Participants & Analysis and Quality \\
\hline $\begin{array}{l}\text { - Authors: Thepha et al. (2018) } \\
\text { - Location: Thailand } \\
\text { - Study Aim: To identify perceived facilitators and } \\
\text { barriers to exclusive breastfeeding for } 6 \text { months in } \\
\text { Northeast Thailand. } \\
\text { - Design: Cross-sectional } \\
\text { - Platform: General social media, including } \\
\text { Facebook }\end{array}$ & $\begin{array}{l}\text { - Criteria: Northeast Thai mothers }(20-40 \\
\text { years), primiparous and multiparous }(4-6 \\
\text { months). Currently or previously } \\
\text { breastfeeding. } \\
\text { - Recruitment: Self-selected sample from } \\
\text { recruitment posters at three hospitals. } \\
\text { Characteristics: } \mathrm{n}=30(100 \% \text { female); } \\
\text { Mean age: } 30(\mathrm{SD}=5.49) \text {; Range }=20 \text { - } \\
\text { 40. }\end{array}$ & $\begin{array}{ll}\text { - } & \text { Thematic analysis. } \\
\text { - } & 0.70\end{array}$ \\
\hline $\begin{array}{l}\text { - Authors: Gallegos et al. (2011) } \\
\text { - Location: Australia } \\
\text { - Study Aim: To explore the potential role of } \\
\text { technology to ameliorate breastfeeding risks. } \\
\text { - Design: Cross-sectional } \\
\text { - Platform: General social media }\end{array}$ & $\begin{array}{l}\text { - Criteria: Women directly involved in the } \\
\text { feeding of infants. } \\
\text { - Recruitment: Via childcare centres. } \\
\text { - Characteristics: } n=41 \text { (100\% female); } \\
\text { Range = 20-46 years }\end{array}$ & $\begin{array}{ll}\text { - } & \text { Thematic analysis } \\
\text { via grounded theory } \\
\text { - } & 0.70\end{array}$ \\
\hline $\begin{array}{l}\text { - Authors: Alianmoghaddam et al. (2018) } \\
\text { - Location: New Zealand } \\
\text { - Study Aim: To explore the impact of social media } \\
\text { on exclusive breastfeeding practice. } \\
\text { - Design: Longitudinal, (monthly up to six months } \\
\text { or cessation) } \\
\text { - Platform: Facebook, Skype }\end{array}$ & $\begin{array}{l}\text { Criteria: Women within postpartum } \\
\text { period intending to breastfeed. } \\
\text { Exclusions: breastfeeding contraindicated } \\
\text { for medical reasons, mental illness } \\
\text { diagnosis, multiple pregnancies, specific } \\
\text { drug use/treatments. } \\
\text { Recruitment: Public advertisements, } \\
\text { social media, and snowballing. } \\
\text { Characteristics: } n=30(100 \% \text { female }) ; \mathrm{Up} \\
\text { to } 25 \text { years } n=2 ; 25-35 \text { years } n=18 ; 35 \\
\text { years or above } n=10 \text {. }\end{array}$ & $\begin{array}{ll}\text { - } & \text { Thematic analysis. } \\
\text { - } & 0.55\end{array}$ \\
\hline
\end{tabular}




\begin{tabular}{|c|c|c|}
\hline Study Characteristics & Participants & Analysis and Quality \\
\hline $\begin{array}{l}\text { - } \text { Authors: Kallem et al. (2018) } \\
\text { - } \quad \text { Location: United States } \\
\text { Study Aim: To identify types of health questions } \\
\text { asked by low-income mothers on a social media } \\
\text { - } \quad \text { Desenting group, and accuracy of replies. } \\
\text { - } \quad \text { Platform: Facebook }\end{array}$ & $\begin{array}{l}\text { - Criteria: Receiving prenatal care at } \\
\text { location, } 18 \text { years plus, provide informed } \\
\text { consent, literate, enrolled in Medicaid, } \\
\text { obese or overweight, planning for care at } \\
\text { hospital, held a smartphone and data plan, } \\
\text { technological skills to take photos or } \\
\text { videos. } \\
\text { Recruitment: Recruited via obstetric } \\
\text { appointments. Part of a wider RCT } \\
\text { looking at a Facebook group intervention } \\
\text { aimed at promoting healthy growth. } \\
\text { Characteristics: } \mathrm{n}=43(100 \% \text { female); } \\
\text { Mean } 25.8 \text { years }(\mathrm{SD}=5.2)\end{array}$ & $\begin{array}{ll}\text { - } & \text { Content analysis. } \\
\text { - } & 0.50\end{array}$ \\
\hline $\begin{array}{l}\text { - } \text { Authors: Majee et al. (2017) } \\
\text { - Location: United States } \\
\text { - Study Aim: To examine interrelational-, } \\
\text { organisational-, and community-level influences } \\
\text { on how co-parents collaborate about infant and } \\
\text { toddler feeding. } \\
\text { - Design: Cross-sectional } \\
\text { - Platform: General social media }\end{array}$ & $\begin{array}{l}\text { - Criteria: Mother-father dyads } \\
\text { - Recruitment: Recruited via two rural } \\
\text { pediatric clinics. } \\
\text { - Characteristics: } n=48 \text { ( } 50 \% \text { female). }\end{array}$ & $\begin{array}{ll}\text { - } & \text { Thematic analysis. } \\
\text { - } & 0.45\end{array}$ \\
\hline
\end{tabular}

